\title{
A Message from BHAC Board President
}

It certainly is an unprecedented time in our world with the coronavirus (COVID-19) pandemic. Life for everyone has drastically changed and brought forth so much uncertainty as well as a change in the way we function every day. Millions of Americans have either been furloughed from their jobs or have lost them, resulting in tremendous financial adversity for so many families. As students returned home from schools and institutions of higher learning throughout the country, education converted from on-site to on-line. Parents with children who were fortunate to keep their jobs are struggling with balancing work and home responsibilities. Stress, anxiety and depression, which were already at epidemic levels before COVID-19, have accelerated to even greater heights. Before this pandemic, 1100 students committed suicide on college campuses every year. We must now get ready for a tsunami of mental health problems as COVID-19 continues and in its aftermath.

Our mental health paradigm must shift in this country from one of crisis intervention to prevention. We will always need to be skilled in crisis intervention, but we must realize that prevention is not an expense; it is an investment that will have great dividends in the future. Every adversity brings new opportunities and this pandemic provides us with a venue to strengthen resiliency in our students, faculty, staff, families, communities and our country.

Our National Consortium for Building Healthy Academic Communities (BHAC) is banning together to promote the health and well-being of students, faculty and staff across the country. We are offering on-line seminars and tips like the one below to equip our academic institutions with important knowledge and skills to help them weather this storm in a resilient way. At the same time, we are planning our 4th National Biennial Summit, which will be held April 21-23, 2021 at the University of North Carolina at Wilmington. See https://healthyacademics.org. In addition, our terrific BHAC journal contains a wealth of evidence to guide best practices.

An organization is only as strong as its members. We are fortunate to have a group of Universities and individual members who work tirelessly to create comprehensive wellness cultures and enhance population health and well-being for all. If you are not currently a member of BHAC, please join us as we strive to create a healthier nation.

Remember, rainbows follow rain. There will be silver linings that come from this pandemic. I am confident that we will get through this together and be stronger as a result.

Warm and well regards,

Bernadette Mazurek Melnyk, PhD, APRN-CNP, FNAP, FNAP, FAAN

President, the National Consortium for Building Healthy Academic Communities

Vice President for Health Promotion

University Chief Wellness Officer

Dean and Professor, College of Nursing

Professor of Pediatrics and Psychiatry, College of Medicine

Executive Director, the Helene Fuld Health Trust National Institute for Evidence-based Practice

The Ohio State University

(C) 2020 Melnyk. This article is published under a Creative Commons Attribution-NonCommercial-NoDerivatives 4.0 International License (https:/ / creativecommons.org/licenses/by-nc-nd/4.0/) 